\title{
The impact of shoe flexibility on gait, pressure and muscle activity of young children. A systematic review
}

\author{
Simone Cranage ${ }^{1,3^{*}} \mathbb{D}$, Luke Perraton ${ }^{1}$, Kelly-Ann Bowles $^{2}$ and Cylie Williams $s^{1,2,3}$
}

\begin{abstract}
Background: There is limited evidence of shoe impact in younger children, particularly in the context of immature gait patterns. It is unclear if the impact from shoes in younger children is similar to what has been seen in older children. This systematic review aims to identify any impact of shoe features on younger children's gait, and if there are any differences between shoe sole flexibility compared to barefoot.

Methods: Study inclusion criteria included: typically developing children aged $\leq 6$ years; comparison of barefoot and shod conditions (walking and/or running) with shoe features or style of shoe described; sample size $>1$. Novelty types of footwear were excluded, as was any mention of in shoe support or modifications. Studies were located from six databases. Study methodology was assessed using the McMasters critical review form. Sample size weighted standardized mean differences (SMD) and 95\% confidence intervals (CI) were calculated.

Results: Four studies were included. Participant age ranged from 15.2 to 78.7 months, with 262 participants across all studies. All studies had limited methodological bias based on their design type. Compared to barefoot walking, shoes increased velocity, step time and step length. Shod walking decreased cadence. Peak plantar pressure was generally lower in the stiff shoe design and there was a higher peak plantar pressure in the Ultraflex shoes. No studies were found investigating muscle activation.

Conclusions: Shoes affect younger children's gait in spatiotemporal gait aspects, similar to those seen in older children. There is limited evidence on effects of particular shoe features such as sole hardness, on gait, and no evidence of any changes in muscle activation patterns. Further research is required to evaluate the impact of different types of shoe and shoe features in this population to provide clinical advice on the type of shoe that is appropriate in this age group.
\end{abstract}

Keywords: Shoes, Footwear, Gait, Child, Toddler, Walk, Run

\section{Background}

Mature gait patterns are well established in children by the age of 3 years [1]. Typical indicators of the establishment of mature gait include the presence of a reciprocal arm swing and heel strike. There is also an increase in velocity, step length and single support together with a reduction in cadence [1]. Studies observing the gait of children between the ages of 1 to 10 years have found that normalised velocity and step length increases gradually

\footnotetext{
* Correspondence: simone.cranage@monash.edu

${ }^{1}$ Department of Physiotherapy, Monash University, Melbourne, Australia

${ }^{3}$ Peninsula Health, Melbourne, Victoria, Australia

Full list of author information is available at the end of the article
}

from 1 to 4 years and stabilises between 5 to 10 years of age [2]. Young children's walking and running is often less stable and less efficient than that of older children and adults due to a higher centre of gravity; lower muscle to body weight ratio; an immature nervous system and poorer postural control [1].

Health professionals and members of the public often advise parents to allow their toddlers to be barefoot as much as possible, or to wear soft soled shoes in the early developmental stages of walking [3]. This is thought to allow an increase in muscle strength in their feet and to assist in sensory experiences with different surfaces. Health professionals and shoe manufacturers often give 
advice based on the assumption that a shoe should not affect normal foot function or motor development in younger children and therefore be as close to barefoot walking as possible [3]. However, there is limited research evidence to guide these shoe recommendations in younger children.

There is also limited research to guide health professionals on the impact of shoes on the gait of children. This is predominantly in children over the ages of six years [4]. Older children walking in shoes resulted in an increased walking velocity, longer stride length, increased stride time, decreased cadence, wider base of support, later toe off time during the gait cycle, increased double support time and a longer stance time, than when walking barefoot [5].

There has also been an observation of changes in lower limb kinetics with shoes changing tibialis anterior activity (compared to barefoot in children with a mean age of 7.7 years (range 2-15 years) [6]. In another study, shoes were also noted to decrease the intrinsic motion of the foot, which could indicate possible splinting effect of shoes on foot joints, a study undertaken with children aged above six years [7].

There is limited available evidence on shoe impacts in younger children, particularly in the context of an immature gait pattern. It is particularly unclear if there are similar impacts from shoes in younger children as seen in their older counterparts. The primary aim of this systematic review was to examine the impact of shoe features on younger children's gait. The secondary aim was to investigate any differences between shoe sole flexibility compared to barefoot gait.

\section{Method}

\section{Search strategy}

This review was undertaken in accordance with the Preferred Reporting Items for Systematic Reviews and MetaAnalysis (PRISMA) guidelines [8]. Two reviewers (SC, $\mathrm{CW}$ ) examined six databases from inception to April 2018. Databases searched were: OVID Medline, EMBASE, CINAHL, EBM reviews, AMED and Sports Discus. Search terms included synonyms of: child, infant, pediatric, gait, walk, jog, run, ambulation stride, step, swing, pressure, force, kinematics, kinetics, angle, spatiotemporal, EMG, electromyography, gait, GAITrite, Trigno, footwear, shoe\$, trainer\$, sole, boot\$, sandal\$, stiffness, hardness, Velcro, buckle, lace, fasten* (Limiter for full text publications and human studies). Boolean operators "AND" and "OR" were used to combine search terms relating to the search question. Where search term variations existed, truncation $(*)$ was used. All research designs were included. An example search strategy for Ovid Medline is outlined (Table 1). Studies were only included if they were published in a peer reviewed journal.
Table 1 Search and selection process for the review studies

\begin{tabular}{|c|c|}
\hline 1. & Child \\
\hline 2. & Infant \\
\hline 3. & P(a)ediatric \\
\hline 4. & Walk \\
\hline 5. & Jog \\
\hline 6. & Run \\
\hline 7. & Ambulat\$ \\
\hline 8. & Stride \\
\hline 9. & Step \\
\hline 10. & Swing \\
\hline 11. & Pressure \\
\hline 12. & Force \\
\hline 13. & Kinematic\$ \\
\hline 14. & Spatiotemporal \\
\hline 15. & Electromyography \\
\hline 16 & Gait \\
\hline 17. & Trigno \\
\hline 18. & Footwear \\
\hline 19. & Trainer\$ \\
\hline 20. & Sole \\
\hline 21. & Boot\$ \\
\hline 22. & Sandal\$ \\
\hline 23. & Stiff* \\
\hline 24. & $\operatorname{Hard}^{*}$ \\
\hline 25. & Velcro \\
\hline 26. & Buckle \\
\hline 27. & Lace \\
\hline 28. & Fasten* \\
\hline 29. & 1 or 2 or 3 \\
\hline 30. & $\begin{array}{l}4 \text { or } 5 \text { or } 6 \text { or } 7 \text { or } 8 \text { or } 9 \text { or } 10 \text { or } 11 \text { or } 12 \text { or } 13 \text { or } 14 \text { or } 15 \text { or } 16 \\
\text { or } 17\end{array}$ \\
\hline 31. & 18 or 19 or 20 or 21 or 22 or 23 or 24 or 25 or 26 or 27 or 28 \\
\hline 32. & 29 and 30 and 31 \\
\hline 33. & Limit 32 to human \\
\hline
\end{tabular}

\section{Eligibility criteria and screening}

Prior to searching, the research team determined inclusion and exclusion criteria for the study (Table 2). Duplicates were removed from the search yield via Endnote and two authors (SC and $\mathrm{CW}$ ) independently screened the abstracts of all retrieved studies against the eligibility criteria using Covidence [9]. Articles were included for full text review where there was uncertainty from the abstract.

Two authors reviewed the title and abstract (SC, CW) to determine if the study was to be included in a full text screening. Any differing opinions were discussed and 
Table 2 Eligibility criteria

\begin{tabular}{ll}
\hline Inclusion criteria & Exclusion criteria \\
\hline Children aged $\leq 6$ years & $\begin{array}{l}\text { Articles with full text not } \\
\text { published in English }\end{array}$ \\
$\begin{array}{l}\text { Comparison of barefoot and shod } \\
\text { conditions (walking and/or running) }\end{array}$ & $\begin{array}{l}\text { Novelty types of footwear } \\
\text { Typically developing children }\end{array}$ \\
$\begin{array}{l}\text { Orthoses, arch supports or } \\
\text { innersoles mentioned }\end{array}$ \\
$\begin{array}{l}\text { Sampact on gait } \\
\text { Sample size of total participants }>1\end{array}$ & $\begin{array}{l}\text { condition known to impact on } \\
\text { gait }\end{array}$ \\
\hline
\end{tabular}

resolved in person. In cases of non-consensus, a third author's opinion was planned for consultation; however, this was not required. All citations of included articles and reference lists were also screened against the eligibility criteria and any articles meeting the inclusion criteria were also included within this review.

\section{Risk of bias assessment-}

All articles included within the final review underwent methodological assessment using the McMaster critical review form- Quantitative studies [10] which is applicable to Randomised Controlled Trials, controlled trials and cross sectional intervention trials. The tool has fifteen individual assessment points within eight domains. Risk of bias was completed independently by two reviewers (SC and LP) and achieved consensus with further discussions and review from a third and fourth reviewer where required $(\mathrm{CW}, \mathrm{KB})$.

\section{Data management}

Where data suitable for extraction was not available, authors were contacted to provide unpublished data. If there was no response within 4 weeks, these articles were excluded from the final review. Data describing the study sample characteristics; study design; shoe design and features; spatiotemporal measures; and kinetics were extracted by two reviewers independently. Consensus on results was discussed between two reviewers who extracted the data (LP and SC). Means and standard deviations for each group were extracted where data was provided or supplied on request.

\section{Statistical methods}

Participant characteristics were described by means, standard deviations (SD) and frequencies (\%). Data were extracted from each study by age, and where there was greater than one participant per age and per condition gait variables were included for meta-analysis. To satisfy the assumption of independence only the data from right side were used within meta-analysis [11]. Where only means and confidence intervals were reported, the group standard deviations were calculated as per the formula $\mathrm{SD}=\sqrt{ } \mathrm{N} \times$ (upper limit - lower limit)/3.92. Sample size weighted standardized mean differences (SMD) and 95\% confidence intervals (CI) for gait variables were calculated using Stata 13 (StataCorp LP.) with the differences in mean scores between the shoe groups and the mean standard deviation using a random effect model (Mantel-Haenszel method) to account for the use of paired data. SMDs were considered to be statistically significant if their associated CI did not cross zero. Interpretations of strength of the SMDs statistics were based on Cohen's guidelines with small effect $\geq 0.2$, medium effect $\geq 0.5$, and large effect $\geq 0.8$ [12].

\section{Results}

\section{Study selection and design}

A total of 4037 articles were screened by two independent reviewers $(\mathrm{SC}, \mathrm{CW})$. Thirty two studies were included for full text screening based on the eligibility criteria. Five studies met the inclusion criteria and were included in the final review. The search and selection process of the articles is described in Table 1.

One study was subsequently excluded, as the data were only aggregate data reported for children between five to 11 years [13]. Gait variables for the five and six year old children within this paper were unable to be separated from the data of children aged seven and above. The author was contacted however no response was received.

\section{Characteristics of included studies}

Table 3 includes the characteristics of the four included papers. All were cross sectional studies (Level IV evidence on the NHMRC evidence hierarchy). The age of the participants in the included studies ranged from 15.2 months to 78.7 months and there were a total 262 participants in the four studies. Table 3 also provides the gait variables per age and per condition.

There were three studies examining the spatiotemporal features of gait $[5,14,15]$ and one that investigated pressure [16]. There were no studies found that investigated muscle activity. All four included studies examined gait while the young children wore athletic type shoes and compared gait in these to barefoot. Two studies, with the same cohort of participants, standardized the torsional flexibility of the shoes $[14,16]$. The torsional flexibility was assessed by determining the amount of force required to cause angular rotation on each shoe, and results classified shoes into; Ultraflex, Medflex, Lowflex and stiff $[14,16]$. One of these two studies evaluated spatiotemporal measures during walking [14], while one study evaluated plantar pressures during walking [16] and reported the data on the same cohort of children. Running was not assessed in any of the included studies. 
Table 3 Description and methodological approach of studies included in review

\begin{tabular}{|c|c|c|c|c|c|c|c|c|}
\hline Author & Country & Design & $\begin{array}{l}\text { Sample } \\
\text { size }\end{array}$ & $\begin{array}{l}\text { Gender (Female) } \\
\text { n (\%) }\end{array}$ & $\begin{array}{l}\text { Mean age } \\
\text { (SD)months }\end{array}$ & $\begin{array}{l}\text { Gait } \\
\text { type }\end{array}$ & $\begin{array}{l}\text { Shoe conditions included } \\
\text { in analysis }\end{array}$ & $\begin{array}{l}\text { Outcome } \\
\text { measures }\end{array}$ \\
\hline $\begin{array}{l}\text { Buckland, } \\
2014\end{array}$ & USA & $\begin{array}{l}\text { Cross sectional } \\
\text { Repeated measures }\end{array}$ & 25 & $8(32 \%)$ & $15.2(2.0)$ & Walk & $\begin{array}{l}\text { Lace up sneakers (Ultraflex, Medflex, } \\
\text { Lowflex, Stiff) }\end{array}$ & Spatiotemporal \\
\hline $\begin{array}{l}\text { Hillstrom, } \\
2013\end{array}$ & USA & $\begin{array}{l}\text { Cross sectional } \\
\text { Repeated measures }\end{array}$ & 24 & $8(32 \%)$ & $15.2(2.0)$ & Walk & $\begin{array}{l}\text { Lace up sneakers (Ultraflex, Medflex, } \\
\text { Lowflex, Stiff) }\end{array}$ & $\begin{array}{l}\text { Plantar } \\
\text { pressures }\end{array}$ \\
\hline \multirow[t]{2}{*}{$\begin{array}{l}\text { Lythgo, } \\
2009\end{array}$} & Australia & Cross sectional & $\begin{array}{l}69 \\
\text { (5 years) }\end{array}$ & $33(48 \%)$ & $68.4(0.2)$ & Walk & Athletic shoes/runners (own) & Spatiotemporal \\
\hline & & Repeated measures & $\begin{array}{l}140 \\
\text { (6years) }\end{array}$ & $75(54 \%)$ & $78.7(0.3)$ & Walk & & \\
\hline \multirow[t]{2}{*}{$\begin{array}{l}\text { Kennedy, } \\
2018\end{array}$} & Australia & Cross sectional & $\begin{array}{l}1 \\
\text { (4 years) }\end{array}$ & $0(0 \%)$ & 50.9 & Walk & $\begin{array}{l}\text { Optimal (runners) own shoes/sub } \\
\text { optimal (flip flops) own shoes }\end{array}$ & Spatiotemporal \\
\hline & & Repeated measures & $\begin{array}{l}3 \\
\text { (5 years) }\end{array}$ & $2(67 \%)$ & $62.8(5.16)$ & & & \\
\hline
\end{tabular}

\section{Spatiotemporal findings}

There were three studies that reported spatiotemporal changes for barefoot versus shoes (Table 4). Two studies had data available for similar ages and were used within a meta-analysis for the variables velocity, cadence, step time and step length (Figs. 1a, b, c and d). Compared to barefoot walking, shoes decreased cadence $(\mathrm{SMD}=-2.50$, $95 \% \mathrm{CI}=-3.45,-1.54, \quad \mathrm{I}^{2}=87.2 \%$ ), increased step time $\left(\mathrm{SMD} 1.44,95 \% \mathrm{CI}=-0.04,2.91, \mathrm{I}^{2}=95.8 \%\right.$ increased step length $\left(\mathrm{SMD}=5.60,95 \% \mathrm{CI}=4.66,6.55, \mathrm{I}^{2}=66.4 \%\right)$ and may increase velocity, $(\mathrm{SMD}=1.65,95 \% \mathrm{CI}=0.74,2.56$, $\left.\mathrm{I}^{2}=89.9 \%\right)$.

\section{Plantar pressures}

Peak plantar pressures were significantly different across four differing shoe conditions relating to stiffness of shoe sole [16]. Overall, the peak plantar pressure was generally lowest in the stiff shoe design (mean $=9.6, \mathrm{SD}=3.2 \mathrm{~N} / \mathrm{cm} 2$ ) and there was a higher peak plantar pressure in the

Table 4 Velocity, cadence, step time and step length data included within meta-analysi

\begin{tabular}{|c|c|c|c|c|c|c|}
\hline Author & $\begin{array}{l}\text { Mean (SD) } \\
\text { Age month }\end{array}$ & Conditions & $\begin{array}{l}\text { Velocity mean (SD), } \\
(\mathrm{cm} / \mathrm{sec})\end{array}$ & $\begin{array}{l}\text { Cadence mean (SD), } \\
\text { steps/min }\end{array}$ & $\begin{array}{l}\text { Step Time } \\
\text { (cm/sec) } \\
\text { Right only }\end{array}$ & $\begin{array}{l}\text { Step length } \\
(\mathrm{cm}) \\
\text { Right only }\end{array}$ \\
\hline $\begin{array}{l}\text { Buckland, } \\
2014\end{array}$ & $15.2(2.0)$ & Barefoot & $87.3(19.7)$ & & & $26.30(4.30)$ \\
\hline $\begin{array}{l}\text { Buckland, } \\
2014\end{array}$ & $15.2(2.0)$ & $\begin{array}{l}\text { Lace up sneakers } \\
\text { (Ultraflex) }\end{array}$ & $87.70(18.90)$ & & & $28.10(3.70)$ \\
\hline $\begin{array}{l}\text { Buckland, } \\
2014\end{array}$ & $15.2(2.0)$ & $\begin{array}{l}\text { Lace up sneakers } \\
\text { (Medflex) }\end{array}$ & $85.70(19.10)$ & & & $28.10(5.70)$ \\
\hline $\begin{array}{l}\text { Buckland, } \\
2014\end{array}$ & $15.2(2.0)$ & $\begin{array}{l}\text { Lace up sneakers } \\
\text { (Lowflex) }\end{array}$ & $83.10(19.30)$ & & & $27.40(4.40)$ \\
\hline $\begin{array}{l}\text { Buckland, } \\
2014\end{array}$ & $15.2(2.0)$ & Lace up sneakers (Stiff) & $86.00(16.20)$ & & & $28.10(3.70)$ \\
\hline Lythgo, 2009 & $68.4(0.2)$ & Barefoot & $124.80(4.60)$ & $152.60(4.10)$ & $389(11)$ & $48.70(1.10)$ \\
\hline Lythgo, 2009 & $78.7(0.3)$ & Barefoot & $127.5(2.40)$ & $146.30(2.60)$ & $415(8)$ & $52.20(0.90)$ \\
\hline Lythgo, 2009 & $68.4(0.2)$ & $\begin{array}{l}\text { Athletic shoes/runners } \\
\text { (own) }\end{array}$ & $130.30(4.20)$ & $142.80(3.40)$ & $423(10)$ & $54.80(1.20)$ \\
\hline Lythgo, 2009 & $78.7(0.3)$ & $\begin{array}{l}\text { Athletic shoes/runners } \\
\text { (own) }\end{array}$ & $133.50(2.80)$ & $138.40(2.10)$ & $437(10)$ & $57.80(0.90)$ \\
\hline $\begin{array}{l}\text { Kennedy, } \\
2018\end{array}$ & 50.9 & Barefoot & 114.8 & 157.1 & 378 & 44.23 \\
\hline $\begin{array}{l}\text { Kennedy, } \\
2018\end{array}$ & $66.8(5.1)$ & Barefoot & $113.7(14.3)$ & $147.5(15.8)$ & $410(45.1)$ & $46.38(1.3)$ \\
\hline $\begin{array}{l}\text { Kennedy, } \\
2018\end{array}$ & 50.9 & Optimal (runners) & 139.9 & 158.3 & 377 & 53.23 \\
\hline $\begin{array}{l}\text { Kennedy, } \\
2018\end{array}$ & $66.8(5.1)$ & Optimal (runners) & $126.0(9.6)$ & $140.4(14.6)$ & $430(42.7)$ & $54.42(2.8)$ \\
\hline
\end{tabular}



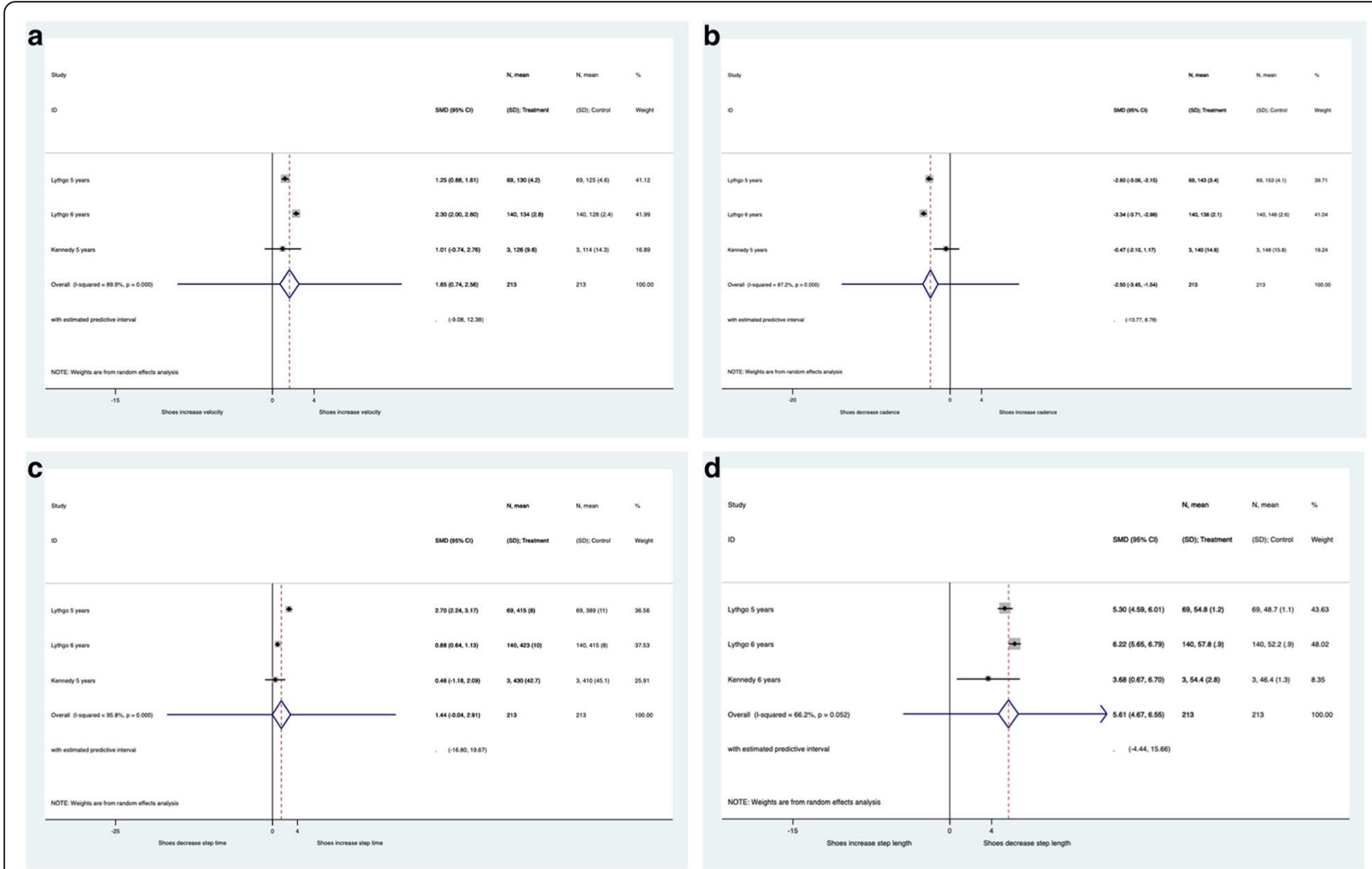

Fig. 1 Forest plots of the differences in a) velocity, b) cadence, c) step time d) step length differences between shoes compared to barefoot walking for young children

Ultraflex shoes $($ mean $=13.0, \mathrm{SD}=3.8 \mathrm{~N} / \mathrm{cm} 2)$. This was the only study that examined pressure variables [16].

\section{Study quality (risk of bias assessment)}

A quality assessment of the articles was completed to assess the risk of bias with the McMaster quantitative critical appraisal tool [10]. All domains were scored for each of the included articles (Table 5). Three studies did not provide a justification of their sample size [14-16]. The clinical importance and clinically meaningful difference between groups were unable to be concluded due to low power within one study [14]. All of the studies included within the review showed good methodology quality for their design type.

\section{Discussion}

The findings of this systematic review are the first to examine the impact of shoes on young children. The previous systematic review of children between the ages of 1.6 years and 15 years, found that children wearing shoes, walk faster by taking longer steps, with an increase in the support phases of the gait cycle [4]. These gait changes may result from footwear increasing the leg length related to the shoe, or an increased mass of the shoe increasing inertia of the leg during the swing phase [4]. The gait changes observed in older children were similar to those observed in younger children within this systematic review. Given the lightweight nature and low shoe base to upper ratio of young children's shoes, it is unknown if shoe height and mass also contribute to these changes in younger children's gait.

Table 5 Methodological quality of the studies included in the review as assessed by the McMasters Quality Assessment

\begin{tabular}{lllllllllllllllll}
\hline Study & 1 & 2 & 3 & 4 & 5 & 6 & 7 & 8 & 9 & 10 & 11 & 12 & 13 & 14 & 15 & Score \\
\hline Buckland [14] & 1 & 1 & 1 & 0 & 1 & 1 & 1 & 1 & 1 & 1 & 1 & 0 & 0 & 1 & 1 & $12 / 15$ \\
Hillstrom [16] & 1 & 1 & 1 & 0 & 1 & 1 & 1 & 1 & 1 & 1 & 1 & 0 & 0 & 1 & 1 & $12 / 15$ \\
Lythgo [5] & 1 & 1 & 1 & 1 & 1 & 1 & 1 & 1 & 1 & 1 & 1 & 1 & 1 & 1 & 1 & $15 / 15$ \\
Kennedy [15] & 1 & 1 & 1 & 0 & 1 & 1 & 1 & 1 & 1 & 1 & 1 & 1 & 1 & 1 & 1 & $14 / 15$ \\
\hline
\end{tabular}


The variability of shoe advice from health professionals may be challenging for parents [17, 18]. Previous studies have described optimum foot development occurring in a barefoot environment with the primary role of shoes being to protect the foot from injury [3]. The results from this systematic review indicate there is an absence of evidence to support one shoe type over another, and limited evidence that shoe flexibility has an impact on young children's gait. While shoes appear to have some influence on gait parameters, it is not yet known if these changes effect function or have any long-term effects on foot health. There are also consistent messages to parents that a stiff and compressive shoe may cause deformity, weakness and loss of mobility [3]. In spite of these negative messages, there are no consistent international and evidence-based recommendations to guide clinicians or manufacturers on the optimal shoe for younger children, in particular whether a child should wear a soft or hard-soled shoe. It is unfortunate that the results of this review indicate that more research is needed rather than providing credible evidence to support either of these recommendations.

This absence of evidence supporting shoe recommendations for children is also a challenge when clinicians are presented with children who have a pathological gait or a foot or lower limb concern. If there is limited literature on typically developing children and shoes, it is difficult to compare the impact of shoes on children with pathological gait. The findings of this review will hopefully encourage future research into the effects of shoe sole features on the gait parameters in children; therefore helping to guide clinicians and shoe industries on the appropriate shoe for younger children.

There are a number of limitations within this review including the limited number of available studies for analysis. It is unknown if the lack of studies is correlated to the challenges that present while testing this age group of children. The psychosocial challenges of having children within a gait laboratory environment is proposed as a large contributing factor to the limited number of studies available to base this review on.

Often gait analysis methods rely on placing markers on small children, which potentially can cause the child to subtly change gait, particularly in young children. The gait environment is also an unappealing play environment therefore challenging to provide ongoing motivation for a younger child to complete all tasks in order to obtain a complete data set during testing.

There was also a limitation in the variability of the shoe and limited descriptions. Like adults, young children wear a variety of shoes including athletic shoes, sandals or boots. It is unknown if the variation in shoe type and their features also contribute to the differences in gait. An additional limitation is the limited number of studies included within the meta-analysis. One of the included studies had a small sample size of four participants for the age range we were interested in [15], therefore, caution should be applied to these results. All full text articles were limited to English which is another limitation of this study.

Further research is required for health professionals to provide recommendations on the optimal shoe characteristics for younger children, including sole hardness. Prospective research is required to determine whether shoe and sole flexibility lead to changes in kinetics, kinematics and muscle activation patterns in younger children and whether changes associated with shoes are associated with clinical and patient-reported outcomes.

\section{Conclusion}

Shoes affect the gait of young children by increasing velocity, cadence, step time and step length compared to bare feet, similar to that of older children. There is limited evidence on the effect of particular shoe features such as sole hardness, on gait and no evidence on any changes in muscle activation patterns. Further research is required to evaluate the impact of different types of shoe and shoe features in this population to provide clinical advice on the type of shoe that is appropriate in this age group.

\section{Acknowledgements}

Not applicable.

\section{Author contribution}

All authors contributed to the review concept and design. SC extracted the data, SC, CMW and LP undertook the article reviews. SC and LP undertook the analysis and all authors contributed to the interpretation. The article was drafted by SC with revision of the article completed by CW, LP and KB.

\section{Funding}

SC is supported through an Australian Government Research Training Program Scholarship. CMW is support by a National Health and Medical Research Council Early Career Health Research Professional Fellowship. This research did not receive any funding.

\section{Availability of data and materials}

Please contact author for data requests.

Ethics approval and consent to participate Not applicable.

\section{Consent for publication}

Not applicable.

\section{Competing interests}

The authors declare that they have no competing interests.

\section{Author details}

'Department of Physiotherapy, Monash University, Melbourne, Australia. ${ }^{2}$ Department of Community Emergency Health and Paramedic Practice, Monash University, Melbourne, Australia. ${ }^{3}$ Peninsula Health, Melbourne, Victoria, Australia. 
Received: 25 September 2019 Accepted: 18 November 2019

Published online: 29 November 2019

\section{References}

1. Sutherland DH, Olshen R, Cooper L, Woo SL. The development of mature gait. J Bone Joint Surg Am. 1980;62(3):336-53.

2. Dusing SC, Thorpe DE. A normative sample of temporal and spatial gait parameters in children using the GAITRite electronic walkway. Gait Posture. 2007;25(1):135-9.

3. Staheli LT. Shoes for children: a review. Pediatrics. 1991;88(2):371-5.

4. Wegener C, Hunt AE, Vanwanseele B, Burns J, Smith RM. Effect of children's shoes on gait: a systematic review and meta-analysis. J Foot Ankle Res. 2011;4(3):1-13.

5. Lythgo N, Wilson C, Galea M. Basic gait and symmetry measures for primary school-aged children and young adults whilst walking barefoot and with shoes. Gait Posture. 2009;30(4):502-6.

6. Mueller S, Baur H, Hirschmueller A, Mayer F. Effects of orthotic insoles on biomechanical gait characteristics in healthy children (Poster Session). Isokinet Exerc Sci. 2004;12:80-1.

7. Wolf S, Simon J, Patikas D, Schuster W, Armbrust P, Döderlein L. Foot motion in children shoes: a comparison of barefoot walking with shod walking in conventional and flexible shoes. Gait Posture. 2008;27(1):51-9.

8. Liberati A, Altman DG, Tetzlaff J, Mulrow C, Gøtzsche PC, loannidis JP, Clarke M, Devereaux PJ, Kleijnen J, Moher D. The PRISMA statement for reporting systematic reviews and meta-analyses of studies that evaluate health care interventions: explanation and elaboration. Ann Intern Med. 2009;151(4):W-65-94.

9. Veritas Health Innovation, Covidence systematic review software. In. Melbourne, Australia; 2017.

10. Law M, et al. Guidelines for critical review of qualitative studies. McMaster University Occupational Therapy Evidence-Based Practice Research Group. 1998.

11. Menz HB. Two feet, or one person? Problems associated with statistical analysis of paired data in foot and ankle medicine. Foot. 2004;14:2-5.

12. Cohen J: Statistical power analysis for the Behavioural sciences. In. Hillsdale, NJ: L. Erbaum Associates; 1988.

13. Chen J-P, Chung M-J, Wu C-Y, Cheng K-W, Wang M-J. Comparison of barefoot walking and shod walking between children with and without flat feet. J Am Podiatr Med Assoc. 2015;105(3):218-25.

14. Buckland MA, Slevin CM, Hafer JF, Choate C, Kraszewski AP. Team HfSSPR: the effect of torsional shoe flexibility on gait and stability in children learning to walk. Pediatr Phys Ther. 2014;26(4):411-7.

15. Kennedy RA, McGinley JL, Paterson KL, Ryan MM, Carroll K. Gait and footwear in children and adolescents with Charcot-Marie-tooth disease: a cross-sectional, case-controlled study. Gait Posture. 2018;62:262-7.

16. Hillstrom HJ, Buckland MA, Slevin CM, Hafer JF, Root LM, Backus SI, Kraszewski AP, Whitney KA, Scher DM, Song J, et al. Effect of shoe flexibility on plantar loading in children learning to walk. J Am Podiatr Med Assoc. 2013;103(4):297-305.

17. Davies N, Branthwaite $H$, Chockalingam N. Where should a school shoe provide flexibility and support for the asymptomatic 6- to 10-year-olds and on what information is this based? A Delphi yielded consensus. Prosthetics Orthot Int. 2015;39(3):213-8.

18. Morrison SC, Price C, McClymont J, Nester C. Big issues for small feet: developmental, biomechanical and clinical narratives on children's footwear. J Foot Ankle Res. 2018;11:39.

\section{Publisher's Note}

Springer Nature remains neutral with regard to jurisdictional claims in published maps and institutional affiliations.

Ready to submit your research? Choose BMC and benefit from:

- fast, convenient online submission

- thorough peer review by experienced researchers in your field

- rapid publication on acceptance

- support for research data, including large and complex data types

- gold Open Access which fosters wider collaboration and increased citations

- maximum visibility for your research: over $100 \mathrm{M}$ website views per year

At $\mathrm{BMC}$, research is always in progress.

Learn more biomedcentral.com/submissions 